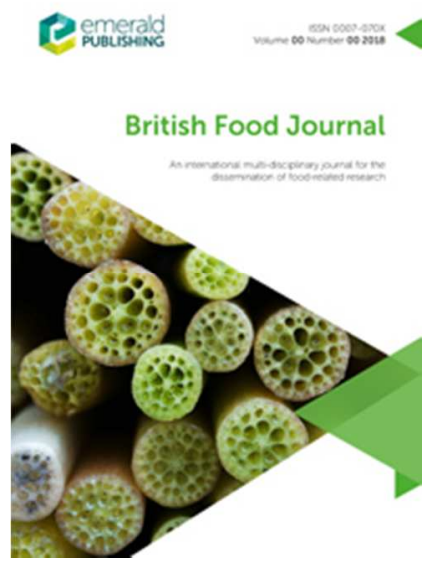

Who are the future seaweed consumers in a Western society? Insights from Australia

\begin{tabular}{|r|l|}
\hline Journal: & British Food Journal \\
\hline Manuscript ID & BFJ-03-2018-0189.R2 \\
\hline Manuscript Type: & Research Paper \\
\hline Keywords: & $\begin{array}{l}\text { Seaweed, Consumers, Neophobia, Snacking, Health consciousness, } \\
\text { Symbolic }\end{array}$ \\
\hline \multicolumn{2}{|l}{} \\
\hline
\end{tabular}

SCHOLARONE ${ }^{\text {m }}$

Manuscripts 


\title{
Who are the future seaweed consumers in a Western society? Insights from Australia
}

\author{
Structured Abstract \\ Purpose: \\ Profile consumers who are likely to eat seaweed products in Australia. \\ Design/methodology/approach:
}

The study was conducted as an online survey among 521 Australian consumers. Binary logistic regression modeling was used to profile the consumers.

\section{Findings:}

Identifies education, familiarity, food neophobia, symbolic value of food consumption, health consciousness, as well as snacking behaviour as significant predictors of likelihood to eat seaweed products. Consumers with a university degree (i.e., undergraduates and postgraduates) are four-times more likely to eat seaweed products, and those familiar with seaweed products have a 7.6 higher likelihood to eat seaweed products. Food neophobia (FNeo) makes the largest contribution to the consumer's likelihood to eat seaweed. A oneunit increase in the FNeo score is associated with a 77\% decrease in the predicted odds of eating seaweed products in the next 12 months. The symbolic value of food consumption and health consciousness both doubled the likelihood of eating seaweed products. Snacking behaviour increases the likelihood by $185 \%$. The study reveals that early adopters of seaweed food products in Western societies are people with higher educational levels, who are adventurous in their food choices and perceive seaweed consumption to have symbolic value. They are also health conscious "snackers".

\section{Originality/value:}

One of the first attempts to provide insights about consumption of seaweed products and it reveals the consumer groups in Western societies that are most likely to eat seaweed products and who can be targeted as potential early adopters.

Key words: Seaweed; Consumers; Neophobia; Snacking; Health consciousness; Symbolic 


\section{Introduction}

Globally, more than 20 million tonnes of seaweed are harvested annually, primarily from China and Indonesia and about half of which is for human consumption as dried product (Paul et al. 2013). Consumers in Asian countries such as China, Japan, Korea, Philippines and Indonesia and also across the Pacific Islands traditionally eat dried and fresh seaweed; however, it is not part of the traditional diet for most western countries with the exception some coastal Atlantic communities such as Ireland, Brittany, Maine and Nova Scotia (Chapman et al. 2015; Fleurence et al. 2012; Prager 2017).

However, seaweed is becoming increasingly popular in Western societies where it is often labelled a superfood because of functional and health benefits (Holdt \& Kraan 2011). Seaweed is now featured on restaurant menus, television cooking shows and is the focus of dedicated cooking books because of its unique textures and flavours compared to land crops (Mouritsen 2013). More broadly, seaweed consumption in the form of sushi and as an ingredient in snack foods such as seaweed flavoured crackers has experienced growth in recent times (Altintzoglou, et al. 2016). An analysis of the seaweed food product market in the UK conducted by Bouga and Combet (2015) indicates growth of the seaweed food category, with 226 different seaweed food products being identified across 10 different product categories (bread, confectionery, condiments, drinks, noodles and pasta, salads, whole seaweed, snacks, soup, supplements and sushi). The products were available for sale by 29 UK retailers, including seven of the major retailers who were stocking $30 \%$ of the seaweed products available.

Even though a myriad of products from Asia are starting to be marketed, and some domestic products emerging, the seaweed industry in most Western Societies such as Australia is 
underdeveloped. Given the extensive Australian coastline and its long-established high biodiversity of seaweed varieties recognized as a global hotspot (Bolton, 1994), it would appear that there are abundant opportunities to exploit the global trend of seaweed consumption. However, very little is known about consumers' perceptions of seaweed as a food product and hence demand. For consumers, an unfamiliar and novel food product such as seaweed can be daunting, and gaining consumer acceptance for a product that many consumers may find intrinsically unappealing will be critical if a seaweed food industry is to succeed.

To the best of our knowledge, empirical studies of seaweed consumption in Western societies have not been published in the academic literature. A recent literature review focused on consumers' perceptions of seaweed food products (Prager 2017) and one other paper based on sensory analysis focused on challenges and opportunities for including seaweed in a Nordic diet (Chapman et al. 2015). To address this gap in the literature, the present study is profiling consumers who are likely to eat seaweed products in a typical Western society, in this case Australia.

\section{Theoretical framework for consumer profiling}

\section{Health consciousness}

Consumers are becoming increasingly health conscious (Beardsworth et al. 2002; Gould 1988; Fagerli \& Wandel 1999; Kubberod, Ueland, Tronstad, \& Risvik 2002; Verbeke, 2005). Seaweed is a functional food which delivers numerous health benefits including the prevention of cardiovascular disease, cancer and diabetes, metabolic syndrome, and digestive track and bone disease (Bouga and Combet 2015; Kumar et al. 2015). Seaweed is gaining 
interest globally as a highly nutritious food rich in antioxidants and beneficial micronutrients such as potassium, magnesium, and iodine (Gupta \& Abu-Ghannam 2011; Roohinejad et al. 2016). In addition, seaweed is high in dietary fibre aids weight loss through enhanced satiety and reduced fat absorption leading to lower risk of cardio vascular disease Hall et al. 2012; Wanyonyi et al. 2017).

\section{Responsibility and food safety concerns}

Consumers are also becoming increasingly conscious of where their food comes from, how it affects the environment, how it is produced and what it contains, including, for example, concerns about chemical and bacterial contamination and the use of preservatives and additives (Pieniak et al. 2008). Concerns about food safety associated with seaweed include the potential presence of allergens and pathogens (Van der Spiegel, et al. 2013). However, allergens linked to seaweed are rare as compared with fish (Fleurence et al. 2012). In terms of environmental benefits, some seaweed species are a very good source of protein and many consumers are turning to alternative and plant-based proteins to reduce their carbon footprint (de Boer et al., 2013; Fleurence et al., 2012; Verbeke, 2015).

\section{Food neophobia}

Neophobia or the unwillingness to try new or unfamiliar foods results in high failure rates for innovative and novel food products (Barrena \& Sanchez 2012; Gresham, et al. 2006; Moreau, et al 2001; Pliner \& Hobden 1992). Aversion, danger and disgust are the three main reasons for neophobia or food rejection (Rozin, et al. 1993). Consuming unfamiliar products such as seaweed may lead to repulsion or what has been termed the 'yuck factor' (Pluhar 2010; Verbeke et al. 2005). Those with lower levels of neophobia include younger people (Loewen \& Pliner, 2000; Tuorila et al., 2001); more educated consumers (Flight et al. 2003), males 
(Meiselman, et al. 1999; Nordin et al. 2004) and urban consumers (Flight, et al. 2003; Tuorila et al. 2001). Hence, despite evident health and environmental benefits, getting consumers in Western societies to replace traditional meats with alternative, arguably more sustainable and unfamiliar sources of protein such as seaweed will be challenging (Chapman et al. 2015; Prager 2017; Schösler et al. 2012).

\section{Symbolic food consumption}

Consumption of certain "trendy" or novel foods can serve an image and social status function and thus seaweed consumption may have some symbolic value for the consumer (Elliot 2014; Jain \& Srinivasan 1990; Kapferer \& Laurent1985; Perrea et al. 2017). For example, Brunsø et al. (2009) found that Belgians considered cooking fish to be "chic", and Juhl and Poulsen (2000) suggested that "it tells something about a person if he/she eats fish". A comparison of Norwegian and Japanese sushi consumers revealed that in addition to health benefits and convenience, eating sushi was considered to be "trendy" (Altintzoglou et al. 2016).

\section{Snacking behavior}

Demand for convenient snacks with nutritional and functional benefits has increased in recent times (Potter, Stojceska, \& Plunkett 2013; Rathod \& Annapure 2016). This propensity for seeking convenient, healthier snack foods represents an attractive opportunity to introduce seaweed into the Western diet. Snacks are a strong growth market estimated to be valued globally at US $\$ 635$ billion by 2020 , with an increasing demand for functional, organic, and natural snacks (Global Industry Analysts 2015).

In line with the framework above, we can expect that the likelihood of adopting seaweed as a food product will be higher among consumers with higher levels of: health consciousness, 
environmental impact and food safety concerns, snacking behavior, and symbolic value orientation in their food choice. In addition, we predict that food neophobia lowers the likelihood of adopting seaweed as a food product. Furthermore, consumer familiarity with seaweed products based on direct consumer experiences or indirect experiences through family/friends and marketing (e.g., cooking shows, restaurant menus) is expected to increase the likelihood of adopting seaweed as a food product. We do not set forth specific hypotheses with respect to potential effects of socio-demographics. However, the effects of gender, age and education level are controlled for during the analysis.

\section{Materials and Methods}

\section{Data collection and sample}

A national online survey of Australian consumers $(n=521)$ was administered in November 2017 through a Qualtrics online consumer panel. Because the Qualtrics panel sample is not a "probability sample", meaning that it will not provide a national representation, we aimed for at least 500 respondents to ensure that there were sufficient numbers $(>100)$ in each age demographic. The survey contained questions regarding current seaweed consumption, attitudes toward seaweed as a food product, perceptions of benefits and risks, drivers and barriers to seaweed consumption, preferences and consumption occasions. To profile consumers of seaweed products, relevant constructs such as health consciousness, responsibility and concern about food safety, neophobia, snacking behaviour, and symbolic value as well as relevant demographics were measured.

A profile of the respondents is provided in Table 1. Given respondents were screened for being at least a joint grocery shopper for the household, responses were skewed towards females. The sample is reasonably representative of the overall Australian population in 
terms of age, education and income level as well as ethnicity. The respondent's mother's ethnic background showed that $62 \%$ were white Australian, $18 \%$ European, 10\% Asian, 2.7 $\%$ New Zealander, and $1.5 \%$ indigenous Australian or Islander. The remaining $5.8 \%$ were, Middle Eastern, African, American or Canadian. The respondent's state of residence showed that $31 \%$ reside in New South Wales, $25 \%$ in Victoria, $21 \%$ in Queensland, $11 \%$ in Western Australia, $8 \%$ in South Australia, and the remaining 4\% in Tasmania, Northern Territory or the Australian Capital Territory.

\section{Insert Table 1 about here}

\section{Questionnaire and scaling}

In order to distinguish seaweed consumption from sushi consumption, which we suspected was the most prominent form of seaweed consumed in Australia, the respondents were first introduced to the purpose of the survey. After responding to socio-demographic questions, a series of open-ended questions related to seaweed were asked (i.e., "What is the first thing that comes to mind when you hear the word "seaweed"?,"Complete the following sentences: "When I think about eating seaweed, I ...", and "Eating seaweed is ...". The wide range of responses indicate that the respondents were or became aware of seaweed as a wider food category than just sushi wrappings. The likelihood of eating seaweed products in the next 12 months was measured on a 7-point likelihood scale. We also asked respondents if they were aware that Sushi wrappers were made from seaweed as a proxy for self-reported familiarity.

Food neophobia was measured on 10 items, with eight selected from Pliner and Hobden's (1992) Food Neophobia Scale (FNeo) and two items from the food-related lifestyle instrument (Brunsø \& Grunert 1995). To measure health consciousness, we selected 4 items 
from Gould's (1990) health consciousness scale. Responsibility with food and food safety concern items were based on items from the revised Food Related Lifestyle Instrument (Birch, Brunsø, Grunert \& Memery 2017). To measure symbolic value, we used three items from Kapferer \& Laurent's (1985) and Jain and Srinivasan's (1990), CIP (consumer involvement profile) scales. Measures for snacking behaviour was based on items in the original food related lifestyle instrument (Brunsø \& Grunert 1995).

\title{
Insert Table 2 about here
}

\begin{abstract}
A principal factor analysis was conducted on the 26 items with orthogonal rotation (varimax). The Keiser-Meyer-Olkin measure verified the sampling adequacy for the analysis, $\mathrm{KMO}=$ .86 (Field, 2013). An initial analysis was run to obtain eigenvalues for each factor in the data. Five factors had eigenvalues over Kaiser's criterion of 1 and in combination explained 71.99 $\%$ of the variance. We retained all five factors because of the relatively large sample size and the convergence of the scree plot and Kaiser's criterion on this value (see Table 2). The first factor is labelled Responsibility/food safety. The Cronbach's Alpha is .88 after deleting one item. The second factor is labelled Neophobic. We removed six items with factor loadings less than .77 . The Alpha is .85 for the remaining four items. The third factor is labelled Health consciousness and the Alpha is .85 . The fourth factor is labelled Symbolic value (Alpha .88), and the final, fifth factor is labelled Snacking behaviour (Alpha .85). Summated scales are made from the factors and used in the subsequent analyses.
\end{abstract}




\section{Statistical modelling}

We analyse the likelihood to eat seaweed products in the next 12 months as a discrete decision (likely/unlikely). The response categories "highly likely" $(\mathrm{n}=100)$, very likely" $(\mathrm{n}=$ 78), and "likely" $(\mathrm{n}=94)$ are specified as "likely" $(62 \%)$. The response categories "not at all likely" ( $\mathrm{n}=107)$, "very unlikely" $(\mathrm{n}=33)$, and "unlikely" $(\mathrm{n}=27)$ are specified as "unlikely (38\%). Respondents who indicated "neither likely nor unlikely" $(\mathrm{n}=80)$ are excluded from the analyses. Modelling the likelihood of eating seaweed products the next 12 months as a dichotomous decision is consistent with the suggestions by Hoek et al. (2011) and Verbeke (2015).

Given the non-normal distribution of the consumption likelihood, binary logistic regression is used to model the dichotomous decision. The complete empirical specification is given by the following equation:

$$
\begin{aligned}
\text { Seaweed }_{i}= & \beta_{0}+\beta_{1} \text { male }_{i}+\beta_{2} \text { Age }_{i}+\beta_{3} \text { Edu }_{i}+\beta_{4} \text { Fam }_{i}+\beta_{5} \text { FNeo }_{i}+\beta_{6} \text { FSafe }_{i} \\
& +\beta_{7} \text { FSymV }_{i}+\beta_{8} \text { FHealth }_{i}+\beta_{9} \text { FSnack }_{i}+\varepsilon_{i} .
\end{aligned}
$$

Gender, education and familiarity are specified as dummy variables. We explored alternative specifications where we included interaction effects. However, no model performed better in predicting Seaweed $_{i}$ than the main effects model. We used maximum likelihood estimation for regression coefficients. They are presented with Wald $\mathrm{X}^{2}-$ statistics and as odds ratios (i.e., the exponentiated logistic regression parameters or the ratio between the probability that a respondent is likely or unlikely to eat seaweed products in the next 12 months). 


\section{Results \\ Descriptive statistics}

Of those respondents who are sure if they have eaten seaweed or not $(n=502), 74 \%$ report that they have eaten seaweed. However, consumption of seaweed is relatively low with only $37 \%$ of the respondents having eaten seaweed more than once a month in the past 12 months. Of those who indicated that they were either likely or unlikely to eat seaweed in the next 12 months, $62 \%$ indicated it would be likely. Those who had eaten or tasted seaweed in the past are more likely to eat seaweed in the next 12 months (77\%) than those who have not tasted seaweed in the past $(8 \%)\left(\mathrm{X}^{2}=149.84, \mathrm{p}=.000\right)$. The majority $(84 \%)$ were aware that sushi wrappers are made from seaweed.

Respondents with a preference for eating red meat, pork or chicken over fish/seafood were significantly less likely to have ever eaten seaweed $\left(X^{2}=9.56, p=.02\right)$, consumed seaweed in the past 12 months $\left(X^{2}=16.59, p=.01\right)$, or to consume seaweed in the next 12 months $\left(X^{2}\right.$ $=29.28, \mathrm{p}=.00)$. Contrary to expectations, vegetarians, vegans and pescetarians indicated lower likelihood of consuming seaweed in the next 12 months, indicating that they may be unaware of the high protein content in some species of seaweed.

\section{Insert Table 3 about here}

The respondents' mean score on food neophobia (FNeo) is 3.5 and just above the mid-point of the scale (Table 3 ). Highest average scores were for health consciousness $($ FHealth $=4.76$ ) and responsibility with food and food safety $($ FSafe $=4.87)$. Pearson correlation between FHealth and FSafe amounted to .66 ( $<$.01) (Table 3). By contrast, lower scores were 
reported for on the symbolic value of food consumption (4.18) and food snacking behaviour (3.78).

Respondents with a university educational level attach significantly more importance $(\mathrm{t}=$ $2.73 ; \mathrm{p}=.006)$ to the symbolic value of food consumption $($ mean $=4.4)$ compared with respondents with lower/vocational educational levels $($ mean $=4.0)$. The respondents with a university degree are also more health conscious than non-university educated (mean $=4.9$ vs. 4.6. $\mathrm{t}=1.74 ; \mathrm{p}=.082$ ).

\section{Binary logistic regression results}

The results of the binary logistic regression model are presented in Table 4 . The estimated logistic regression coefficients ( $\left(\right.$ ) with respective standard errors (S.E.), Wald $\mathrm{X}^{2}$-statitics, significance levels, odds ratios $(\operatorname{Exp}(\beta))$, and goodness-of-fit statistics are presented. The correlation coefficients presented in Table 4 and the small standard error (S.E.) of the coefficient estimates and collinearity diagnostics (smallest tolerance value $=.50$ ) indicate that multi-collinearity is not a major concern in the model.

\section{Insert Table 4 about here}

Gender and age have no significant effect on likelihood to consume seaweed in the next 12 months. However, respondents with a university degree are 4 times more likely to eat seaweed products in the next 12 months as compared with less educated respondents. Respondents who were familiar with seaweed products (i.e., aware that sushi rolls are wrapped in seaweed), are 7.6 times more likely to eat seaweed products. Food neophobia (FNeo) is the most significant predictor of respondents' likelihood to eat seaweed products in 
our model (Wald $X^{2}=56.84$ ). One unit increase in the food neophobia score is associated with a $77.2 \%$ decrease in the predicted odds of likelihood to eat seaweed products.

Significant effects of seaweed choice motives are also produced by the perceived symbolic value of food consumption (FSymV), health consciousness (FHealth), and snacking behaviour (FSnack). An increase of one unit in the importance respondents attach to the symbolic value of food consumption, increases the likelihood of eating seaweed products in the next 12 months by $233 \%$. A one unit increase in the respondents' health consciousness is associated with a $197 \%$ increase in the predicted odds to eat seaweed products. Finally, an increase of one unit in a respondent's snacking behaviour increases the likelihood of eating seaweed products in the next 12 months by $185 \%$. Responsibility with food and food safety concern (FSafe) has no significant effect on the likelihood to eat seaweed products.

Further, we developed two profiles of consumers and calculated predicted probabilities of eating seaweed products in the next 12 months. In Profile 1, the probability to eat seaweed products of a highly educated consumer who is familiar with seaweed products is indicated. $\mathrm{He} / \mathrm{she}$ attaches a rather higher importance to the symbolic value of food consumption FSymV $\geq 5$ ), has a more frequent snacking behaviour (FSnack $\geq 4$ ) and is typically more health conscious (FHealth $\geq 4$ ). The food neophobia score for this consumer profile has no impact on the probability to eat seaweed products in the next 12 months. The probability is close to $100 \%$ for all levels of food neophobia. Within our sample, $8.4 \%$ of the higher educated consumers who are familiar with seaweed products correspond with this profile.

The contrasting Profile 2 include lower educated consumers who are not familiar with seaweed products. They attach lower importance to the symbolic value of food consumption 
$($ FSymV $\leq 3)$, have a less frequent snacking behaviour $($ FSnack $\leq 3)$ and a lower level of health consciousness (FHealth $\leq 4)$. Up to a food neophobia score of 3 (scale mid-point), this consumer's probability to eat seaweed products is $93 \%$ or more. We see a decrease in the probability with a food neophobia score higher than 3. Even with the highest degree of food neophobia, this consumer still has a probability of $43 \%$ to eat seaweed products in the next 12 months. A small number (3.6\%) of lower educated respondents who are unfamiliar with seaweed products correspond with this profile. The two consumer profiles highlight food neophobia combined with education level and familiarity as boundary conditions related to the likelihood to eat seaweed products.

\section{Discussion and conclusions}

\section{Discussion}

The purpose of the present study was to investigate the likelihood of 'typical' Western consumers to eat seaweed products and personal and food-related attitudinal predictors of this likelihood. However, we acknowledge that the geography and cultural differences of Australia may influence comparisons with other western societies. We know that Australia has been negatively impacted by a preference for high fat, salt and sugar diets, but that in recent times Australians are searching healthier food options (Ridoutt et al. 2016). From the seaweed consumption perspective, there may be differences in the timing of the sushi boom that has brought seaweed awareness to the west, arriving in Europe in the 1990s (Cwiertka 2005) and earlier to the US in the 1960s (House 2018). We suspect that a similar boom happened in Australia after 1995, which would explain the large increase in dried seaweed consumption (Ridoutt et al. 2016): in 1995 adult consumption was $<0.01 \mathrm{~kg} /$ person/year but in 2011 this was $0.03 \mathrm{~kg} /$ person/year (a 400\% increase, the largest across all food categories examined). In this context, it is not surprising that three-quarters of our Australian 
respondents have eaten or tasted seaweed in the past, even though the consumption frequency is relatively low. Just less than two-thirds of the respondents indicated that it would be likely they would eat seaweed products in the next 12 months.

While females and younger consumers reported higher levels of seaweed consumption in the past 12 months, neither gender nor age had any impact on the likelihood to eat seaweed products in the next 12 months. Likewise, a study of sushi consumers in Norway and Japan, Altintzoglou, et al. (2016) also found no age effect among Norwegian consumers (i.e., a Western society). These findings may indicate is that the relationship between past experience and future intentions is highly asymmetrical. While the overall relationship is positive, $23 \%$ of those who had consumed seaweed in the past did not report intention to eat seaweed products in the next 12 months. Hence, lower intention to consume in the future may have resulted from disappointing past experiences with eating seaweed. Another possibility is that these findings may indicate that age is becoming less of a predictor of food consumption patterns in Western Societies, and may reflect that consumers across all age categories are becoming more receptive to new and novel food products, in particular those which are a healthier or more sustainable option.

Our study revealed that higher educational levels significantly influence the likelihood of eating seaweed products. Likewise, de Boer et al. (2013) found that a higher level of education had a positive impact on the choice of snacks made from environmentally-friendly proteins including lentils and seaweed. Schösler et al. (2012) also found the level of education had a positive impact on choice of different components of meat substitution options (i.e., soy, gourmet vegetarian, convenience components. 
In line with previous studies of food consumption (e.g., Verbeke 2015), familiarity is a driver for consuming seaweed products. We used the respondent's awareness that sushi wrappers are made from seaweed as a proxy for familiarity. Consumers may not be less aware of other seaweed products or products with seaweed as a minor ingredient (e.g., rice crackers). Food neophobia is the single most influential factor in predicting consumers' likelihood to eat seaweed products. Consuming unfamiliar products such as seaweed leads to repulsion among many consumers and the so-called 'yuck factor' is strongly present among Australian consumers (Pluhar 2010; Verbeke et al. 2005). Consumers of seaweed products are more likely to be neophilic, adventurous with food and willing to try new products (Altintzoglou et al. 2016). The perceived symbolic value of food consumption had a significant effect on seaweed choice motives. Seaweed is a novel food product in Western societies and obviously serves as an image and social status function. This is similar to the findings of Juhl \& Poulsen (2000) and Altintzoglou et al. (2016). The observed effect of snacking behaviour suggests that seaweed products are appealing as a snack. This is consistent with the findings by Verbeke (2015) and Schösler et al. (2012).

\section{Practical implications}

This study is one of the first attempts to provide insights about consumption of seaweed products and it reveals the consumer groups in Western societies that are most likely to eat seaweed products. These insights provide input for relevant market positioning, product innovations, and communication strategies. To capitalise on the growing acceptance of seaweed products in Western societies, creative positioning of seaweed may help to pave the way for increasing human consumption of seaweed. Developing convenient and sophisticated seaweed products to appeal to higher educated consumers will lead to increased seaweed consumption. Given, neophobia is a major obstacle for consuming seaweed, managing the 
sensory characteristics of seaweed including smell, appearance and texture will be critical to wider market acceptance. Avoiding aversion or disgust and identifying more palatable seaweed products, such as including seaweed as a minor ingredient in other more familiar products will lead to greater consumer acceptance (Chapman et al. 2015). Conversely, consumers of seaweed (and sushi) are more likely to be adventurous with food and willing to try new products (Altintzoglou et al. 2016). Providing innovative seaweed products and facilitating trial and experimentation by ensuring seaweed products are featured on menus, cooking shows and websites and recipe books will encourage consumption by these more adventurous food consumers. More health conscious consumers are a primary market for seaweed (Prager 2017), hence new product development and marketing campaigns need to accentuate the significant health and nutritional benefits of seaweed consumption. Seaweed consumers are also more likely to assign symbolic value to food choices, and therefore capitalising on the association of "you are what you eat" and the potential for seaweed to be considered to be a chic or trendy food choice should underpin promotional strategies for new seaweed products. Finally, seaweed consumption is linked to a propensity to snack, representing an opportunity for the seaweed industry to focus on developing healthy, tasty and convenient seaweed snacks.

\section{Limitations and future research}

The focus in our study is on Australian consumers, future studies in other Western societies are recommended to test for generalisability. In our model, we specified the dependent variable as a binary choice. By dichotomizing the original 7-point scale, a potential loss of information is possible. However, given the non-normal distribution of the values, this tactic is defensible based on practical and empirical reasons. An alternative multi- 
nominal logistic regression approach with a three-category response variable contributed little in terms of empirical insights compared with the binary choice modelling.

Our model explained $62 \%$ of the variation in the dependent variable and the other goodness-of-fit statistics are satisfactory. Other predictors of likelihood to eat seaweed products could lead to additional predictive ability, such as disgust (La Barbera et al. 2018; Olatunji, et al. 2009). Martins and Pliner (2006) identified that "animalness/livingness" and aversive textural properties form the basis for disgust reactions towards foods, and studies of reactions to textural properties seems to be particularly relevant in the case of seaweed products. 


\section{Funding:}

This work was funded by an internal university grant

\section{Declarations of interest:}

None 


\section{References}

Altintzoglou, T., Heide, M., Wien, A. \& Honkanen, P. (2016), “Traditional Sushi for Modern Consumers: A comparison between sushi consumption behaviour in Japan and Norway", Journal of Food Products Marketing, Vol. 27 No. 6, pp. 717-732.

Barrena, R. \& Sánchez, M. (2012), “Neophobia, personal consumer values and novel food acceptance", Food Quality and Preference, Vol. 27, pp.72-84.

Beardsworth, A., Bryman, A., Keil, T., Goode, J., Haslam, C. \& Lancashire, E. (2002), "Women, men and food: The significance of gender for nutritional attitudes and choices", British Food Journal, Vol. 104 No. 7, pp. 470-491.

Birch, D., Brunsø, K., Grunert, K. and Memery, J. (2017), “Modular food-related lifestyle: A new instrument for consumer segmentation in food marketing". Conference presentation at the International Food Marketing Research Symposium, June, 2017, Dubrovnik, Croatia.

Bolton, J. J. (1994), “Global seaweed diversity: patterns and anomalies”, Botanica Marina, Vol. 137 No. 3, pp. 241-246.

Bouga, M. and Combet, E. (2015), "Emergence of Seaweed and Seaweed-Containing Foods in the UK: Focus on Labeling, Iodine Content, Toxicity and Nutrition”, Foods, Vol. 4, pp. 240-253; doi:10.3390/foods4020240 
Brunsø, K., \& Grunert, K. (1995), “Development and testing of a cross-culturally valid instrument: Food-related life style", Advances In Consumer Research, Vol. Xxii No. 22, pp. 475-480.

Brunsø, K., Verbeke, W., Ottar Olsen, S., \& Fruensgaard Jeppesen, L. (2009), “Motives, barriers and quality evaluation in fish consumption situations", British Food Journal, Vol. 111 No. 7, pp. 699-716.

Chapman, A., Stevant, P., \& Larssen, W. (2015), “Food or fad? Challenges and opportunities for including seaweeds in a Nordic diet”, Botannica Marina,Vol. 58 No.6, pp. 423-433.

Cwiertka, K.J. (2005), From ethnic to hip: circuits of Japanese cuisine in Europe. Food \& Foodways, Vol. 13, No. 4, pp. 241-272.

De Boer, J., Schösler, H., Boersema, J.J. (2013), “Motivational differences in food orientation and the choice of snacks made from lentils, locusts, seaweed or «hybrid» meat", Food Quality and Preference, Vol. 28, pp. 32-35.

Elliot, C. (2014), “Food as people: Teenagers' perspectives on food personalities and implications for healthy eating, Social Science \& Medicine Vol. 121, pp. 85-90.

Fagerli, Raa \& Wandel, M. (1999), “Gender Differences in Opinions and Practices with Regard to a "Healthy Diet"”, Appetite, Vol. 32 No. 2, pp. 171-190.

Field, A. (2013), “Discovering statistics using IBM SPSS statistics" ( $4^{\text {th }}$ ed.), Sage Publications Ltd., London. 
Fleurence, J., Morancais, M., Dumay, J., Decottignies, P.,Turpin, V., Munier, M., GarciaBueno, N. \& Jaouen, P. (2012), "What are the prospects for using seaweed in human nutrition and formarine animalsraised through aquaculture?", Trends in Food Science \& Technology, Vol. 27, pp. 57-61.

Flight, I., Leppard, P., \& Cox, D. N. (2003), “Food neophobia and associations with cultural diversity and socio-economic status amongst rural and urban Australian adolescents", Appetite, Vol. 41, pp. 51-59.

Global Industry Analysts. (2015), “The Global Snack Food Market”, Available from http://www.strategyr.com/MarketResearch/Snack_Foods_Salted_Baked_Frozen_Snacks_Mar ket_Trends.asp, Accessed 11 January 2018.

Gould, S.J. (1988), “Consumer Attitudes Toward Health and Health Care: A Differential Perspective", Journal of Consumer Affairs, Vol. 22 No. 1, pp. 96-118.

Gould, S.J. (1990), "Health consciousness and health behavior: The application of a new health consciousness scale”, American Journal of Preventive Medicine, Vol. 6 No. 4, pp. 228-237.

Gresham, G., Hafer, J., \& Markowski, E. (2006), “Inter-functional market orientation between marketing departments and technical departments in the management of the new product development process", Journal of Behavioral and Applied Management, Vol. 8 No. 1, pp. 53-65. 
Gupta, S. \& Abu-Ghannam, N. (2011), "Bioactive potential and possible health effects of edible brown seaweeds", Trends in Food Science and Technology, Vol. 22, pp. 315-326.

Hall, A. C., Fairclough, A. C., Mahadevan, K., \& Paxman, J. R. (2012), “Ascophyllum nodosum enriched bread reduces subsequent energy intake with no effect on post-prandial glucose and cholesterol in healthy, overweight males. A pilot study", Appetite, Vol. 58 No. 1, pp. $379-386$.

Hoek, A.C., Luning, P.A., Weijzen, P., Engels, W., Kok, F., \& de Graaf, C. (2011), "Replacement of meat by meat substitutes. A survey on person- and product-related factors in consumer acceptance”, Appetite, Vol. 56, pp. 662-673.

Holdt, S. L. \& Kraan, S. (2011), “Bioactive compounds in seaweed: functional food applications and legislation”, Journal of Applied Phycology, Vol. 23 No. 3, pp. 543-597.

House, J. (2018), Sushi in the United States, 1945-1970. Food and Foodways, Vol. 26, No. 1, pp. $40-62$.

Jain, K. \& Srinivasan, N. (1990), “An Empirical Assessment of Multiple Operationalizations of Involvement”, in Goldberg, M.E., Gorn, G., \& Pollay, R.W. (Eds.), NA - Advances in Consumer Research, Vol. 17, Association for Consumer Research, Provo, UT, pp. 594-602.

Juhl, H and Poulsen C. (2000), “Antecedents and effects of consumer involvement in fish as a product group", Appetite, Vol. 34, pp. 261-267. 
Kapferer, J.-N. \& Laurent, G. (1985), “Consumers' Involvement Profile: New Empirical Results”, in Hirschman, E.C. \& Holbrook, M.B. (Eds.), NA - Advances in Consumer Research, Vol. 12, Association for Consumer Research, . Provo, UT, pp. 290-295.

Kubberød, E., Ueland, Ø., Tronstad, A. \& Risvik, E. (2002), “Attitudes towards meat and meat-eating among adolescents in Norway: a qualitative study", Appetite, Vol. 38 No. 1, pp. 53-62.

Kumar, S. A., Magnusson, M., Ward, L. C., Paul, N. A., \& Brown, L. (2015), “Seaweed supplements normalise metabolic, cardiovascular and liver responses in high-carbohydrate, high-fat fed rats", Marine Drugs, Vol. 13 No. 2, pp. 788-805.

La Barbera, F., Verneau, F., Amato, M., \& Grunert, K. (2018), “Understanding Westerners' disgust for the eating of insets: The role of food neophpbia and implicit associations", Food Quality and Preference, Vol. 64, pp. 120-125.

Loewen, R., \& Pliner, P. (2000), “The food situations questionnaire: A measure of children's willingness to try novel foods in stimulating and non-stimulating situations", Appetite, Vol. 35, pp. 239-250.

Martins, Y. \& Pliner, P. (2006), “Ugh! That's disgusting!": Identification of the characteristics of foods underlying rejections based on disgust”, Appetite Vol. 46, pp. 75-85. 
Meiselman, H. L., Mastroianni, G., Buller, M., \& Edwards, J. (1999), “Longitudinal measurement of three eating behavior scales during a period of change", Food Quality and Preference, Vol. 10, pp. 1-8.

Moreau, P., Lehamann, D. R., \& Markman, A. B. (2001), “Entrenched knowledge structures and consumer response to new products", Journal of Marketing Research, Vol. 38 No. 1, pp. $14-29$.

Mouritsen, O. G. (2013), “Seaweeds: edible, available, and sustainable”, University of Chicago Press.

Nordin, S., Broman, D. A., Garvill, J., \& Nyroos, M. (2004), “Gender differences in factors affecting rejection of food in healthy young Swedish adults", Appetite, Vol. 43, pp. 295-301.

Olatunji, B.O., Moretz, M.W., McKay, D., Bjorklund, F., de Jong, P.J., Haidt, J., Hursti, T.J., Imada, S., Koller, S., Mancini, F., Page, A.C., Schienle, A. (2009), “Confirming the Threefactor Structure of the Disgust Scale - Revised in Eight Countries", Journal of CrossCultural Psychology, Vol. 40 no. 2, pp. 234-255.

Paul, N. A., Tseng, C. K. \& Borowitzka, M. M. (2012), “Seaweed and Microalgae”, in Lucas, J.S. \& Southgate, P.C. (Eds.), Aquaculture (2nd ed.), Blackwell Publishing Ltd., West Sussex, UK, pp. 268-292.

Perrea, T., Krystallis, A., Engelgreen, C., \& Chrysochou, P. (2017), "Much too new to eat it? Customer value and its impact on consumer-product relationship in the context of novel food products”, Journal of Product \& Brand Management, Vol. 26 no. 6, pp. 616-630. 
Pieniak, Z., Verbeke, W., Scholderer, J., Brunsø, K., \& Svein, O. O. (2008), “Impact of consumers' health beliefs, health involvement and risk perception on fish consumption", British Food Journal, Vol. 110 No. 9, pp. 898-915.

Pliner, P., \& Hobden, K. (1992), "Development of a scale to measure the trait of food neophobia in humans", Appetite, Vol. 19 No. 2, pp. 105-120.

Pluhar, E B. (2010), "Meat and morality: Alternatives to factory farming”, Journal of Agricultural and Environmental Ethics, Vol. 23, pp. 455-468.

Potter, R., Stojceska, V., \& Plunkett, A. (2013), “The use of fruit powders in extruded snacks suitable for children's diets", LWT-Food Science and Technology, Vol. 51, pp. 537-544.

Prager, H. (2017), "Investigating the acceptance of seaweed as a viable source of a complete protein", Available from https://www.ntnu.edu/documents/139799/1273574286/TPD4505.Henry.Prager.pdf/bcb465ea $\underline{-79 \mathrm{e} 3-45 \mathrm{c} 0-\mathrm{b} 1 \mathrm{~d} 2-1775 \mathrm{~b} 3 \mathrm{~d} 1852 \mathrm{f}}$, Accessed 23 November 2017.

Rathod, R. \& Annapure, S. (2016), "Effect of extrusion process on antinutritional factors and protein and starch digestibility of lentil splits", LWT-Food Science and Technology, Vol. 66, pp. 114-123.

Ridoutt, B., Baird, D., Bastiaans, K., Hendrie, G., Riley, M., Sanguansri, P., Syrette, J. \& Noakes, M. (2016), Changes in food intake in Australia: Comparing the 1995 and 2011 
National Nutrition Survey Results disaggregated into basic foods. Foods, Vol. 5, No. 2, pp.

40.

Roohinejad, S., Koubaa, M., Barba F., Saljoughian, S., Amid, M., and Greiner, R. (2017),

"Application of seaweeds to develop new food products with enhanced shelf-life, quality and health-related beneficial properties", Food Research International, Vol. 99, pp. 1066 - 1083.

Rozin, P., Haidt, J., \& McCauley, C. R. (1993), “Disgust”, in Lewis, M. \& Haviland, J.M.

(Eds.), Handbook of Emotions, Guilford Press, New York, NY, pp. 575-594.

Schösler, H., de Boer, J., \& Boersema, J. J. (2012), "Can we cut out the meat of the dish?

Constructing consumer-oriented pathways towards meat substitution”, Appetite, Vol. 58, pp. $39-47$.

Tuorila, H., Lahteenmaki, L., Pohjalainen, L., \& Lotti (2001), "Food neophobia among the Finns and related responses to familiar and unfamiliar foods", Food Quality and Preference, Vol. 12, pp. 29-37.

Van der Spiegel, M., Noordam M.Y., Van Der Fels-Klerx, H.J. (2013), “Safety of novel protein sources (insects, microalgae, seaweed, duckweed, and rapeseed)", Comprehensive Reviews in Food Science and food Safety, Vol. 12, pp. 662-678.

Verbeke, W. (2015), "Profiling consumers who are ready to adopt insects as a meat substitute in a Western society", Food Quality and Preference, Vol. 39, pp. 147-155. 
Verbeke, W. (2005), “Consumer acceptance of functional foods: Socio-demographic, cognitive and attitudinal determinants", Food Quality and Preference, Vol. 16 No. 1, pp. 4557.

Verbeke, W., Sioen, I., Pieniak, Z., Van Camp, J., \& De Henauw, S. (2005), “Consumer perception versus scientific evidence about health benefits and safety risks from fish consumption", Public Health Nutrition, Vol. 8 No. 4, pp. 422-429.

Wanyonyi, S., Preez, R. D., Brown, L., Paul, N. A., \& Panchal, S. K. (2017), “Kappaphycus alvarezii as a food supplement prevents diet-induced metabolic syndrome in rats", Nutrients, Vol. 9 No. 11, pp. 1261. 